\title{
Cognitive treatment reduced concerns about shape, weight, and eating in obese binge and non-binge eaters
}

\author{
Nauta H, Hospers $H$, Kok $G$, et al. A comparison between a cognitive and a behavioral treatment for obese binge eaters \\ and obese non-binge eaters. Behavior Therapy 2000 Summer;31:441-61.
QUESTION: In obese binge and non-binge eaters, is cognitive treatment (CT) superior to behavioural treatment (BT) for behaviour and weight outcomes?

Design

Randomised \{allocation concealed*\} $\uparrow$, unblinded,* controlled trial with 6 months of follow up.

\section{Setting}

University in Maastricht, the Netherlands.

\section{Patients}

74 obese (body mass index BMI $\geqslant 27 \mathrm{~kg} / \mathrm{m}^{2}$ ) women who were $18-50$ years of age (mean age $38 \mathrm{y}$, mean BMI $33 \mathrm{~kg} / \mathrm{m}^{2}$ ). Exclusion criteria were participation in a weight loss programme, alcohol or drug dependence, psychosis, or pregnancy. Patients were categorised as binge eaters (meeting all DSM-IV criteria for binge eating disorder $[\mathrm{BED}])(\mathrm{n}=37)$ or non-binge eaters (meeting none of the DSM-IV criteria for BED) $(\mathrm{n}=37)$. Patients were thus excluded if they met some of the $D S M-I V$ criteria for BED. 64 patients $(86 \%)$ completed the treatment.

\section{Intervention}

Patients were allocated to CT or BT according to binge eating status to create 4 groups: CT binge eaters $(n=21)$, CT non-binge eaters $(n=16)$, BT binge eaters $(n=16)$, and BT non-binge eaters $(n=21)$. Both treatments were given in groups for 15 weekly sessions of 150 minutes each. CT was directed at changing dysfunctional cognitions about shape, weight, eating, dieting, and self schemas. BT was directed at learning a healthy eating style, increasing exercise, and anticipating risk situations.

\section{Main outcome measures}

Concerns about shape, weight, and eating, and restraint were measured by the Eating Disorder Examination Questionnaire; weight; depression (Beck Depression Inventory); and self esteem (Rosenberg's Self Esteem Scale). The number of binge eating episodes in 28 days was assessed among binge eaters.

\section{Main results}

Analysis was by intention to treat. Significant treatment $\times$ time interactions were shown between before and after treatment for shape $(p<0.001)$, weight $(p<0.001)$, and eating concern $(\mathrm{p}<0.01)$; CT was superior to BT for all 3 subscales. Obese binge eaters improved more than obese non-binge eaters between before and after treatment for shape, weight, and eating concern. Participants receiving $\mathrm{BT}$ lost more weight than those receiving CT with significant treatment $\times$ time interactions $(p<0.001)$. Binge eaters had a significant weight gain from post treatment to follow up $(\mathrm{p}<0.01)$. More participants in the CT group refrained from binging at follow up than participants in the BT group $(\mathrm{p}<0.01)$. Significant treatment $\times$ time interactions were shown for self esteem $(p<0.001)$. CT was superior to BT for enhancing self esteem between before and after treatment, but not at follow up. Binge eaters improved more in self esteem and depression scores than non-binge eaters.

\section{Conclusions}

In obese binge and non-binge eaters, cognitive treatment (CT) was superior to behaviour treatment (BT) for reducing concerns about shape, weight, and eating, and improving self esteem. CT reduced binge eating more than BT.

*See glossary.

$\dagger$ Information provided by author.

\section{COMMENTARY}

The study by Nauta et al found CT to produce better outcomes than BT in the treatment of obese binge eaters and obese non-binge eaters. This finding adds to other literature supporting the specific benefit of cognitive interventions in the treatment of people with eating disorders. ${ }^{1}$ Interestingly, the results contrast with those of studies comparing the efficacy of CT and BT in the treatment of other psychiatric disorders. Meta-analytic and comparative studies indicate that the 2 treatments produce equivalent outcomes in the treatment of social phobia, ${ }^{2}$ obsessive compulsive disorder, ${ }^{3}$ and post-traumatic stress disorder. ${ }^{4}$

The finding by Nauta et al that CT is more effective than BT in the treatment of obese patients is of particular importance because BT has traditionally been the mainstay of obesity treatment. A Cochrane review of psychological treatments of bulimia nervosa and binge eating concluded that cognitive behavioural therapy (CBT) is superior to waiting list controls but not superior to other psychotherapies with respect to abstinence from binge eating. ${ }^{5}$ Nauta $e t$ al suggest that cognitive interventions used as CBT programmes may not be intensive enough to prompt the necessary learning and implementation of cognitive strategies. This unique study comparing CT and BT challenges current treatment approaches to obese binge eaters and obese non-binge eaters.

Elliot Goldner, MD, MHSc University of British Columbia Vancouver, British Columbia, Canada

1 Fairburn CG, Jones R, Peveler RC, et al. Psychotherapy and bulimia nervosa. Longer-term effects of interpersonal therapy, behavior therapy, and cognitive behavior therapy. Arch Gen Psychiatry 1993;50:419-28.

2 Fedoroff IC, Taylor S. Psychological and pharmacological treatments for social phobia: a meta-analysis. J Clin Psychopharmacol 2001;21:311-24.

3 McLean PD, Whittal ML, Thordarson D, et al. Cognitive versus behavior therapy in the group treatment of obsessive compulsive disorder. J Consult Clin Psychol 2001;69:205-14.

4 Van Etten ML, Taylor S. Comparative efficacy of treatments for post-traumatic stress disorder: a meta-analysis. Clinical Psychology \& Psychotherapy 1998;5:126-44.

5 Hay PJ, Bacaltchuk J. Psychotherapy for bulimia nervosa and binging. Cochrane Database Syst Rev 2000;(2):CD000562. 